\title{
Prevalence of heavy smokers in the year 2000 in the Province of Varese, Italy
}

\author{
A. Imperatori1, N. Rotolo1, V. Conti ${ }^{1}$, D. Di Natale1, V. Tropeano1, W. Mantovani2
}

ABSTRACT: Prevalence of heavy smokers in the year 2000 in the Province of Varese, Italy. A. Imperatori, $N$. Rotolo, V. Conti, D. Di Natale, V. Tropeano, W. Mantovani.

Background. Knowing the prevalence of heavy smokers (HS) by gender and age is a pre-requisite for bringing into effect public health measures against smoking-related diseases. Smoking prevalence data is available for the Italian Regions, however it is generally unknown for the Italian Provinces.

Methods. In the year 2000 a survey of smoking prevalence was conducted by 47 general practitioners (GPs), by personal interview, in a large sample of the Varese Province population 45-74 years of age (28,034 subjects; 13,528 men, 14,506 women). Each surveyed subject was categorised either as ever HS (current/former smoker of at least 10 pack-years) or as non HS. The information on smoking habit collected by the GPs was anonymously pooled for analysis. Prevalence figures of smoking were tabulated by gender and by 5-year age-strata.

Results. In the population 45-74 years of age the percentage of ever HS overall was $22.3 \%$ (34.4\% of men; $11.0 \%$ of women). The prevalence of ever HS in both sexes combined progressively decreased with advancing age, from $23.6 \%$ (45-49 year stratum) to $19.5 \%$ ( $70-74$ year stratum). Current HS were $24.5 \%$ of men and $9.5 \%$ of women.

Conclusions. The year 2000 survey on smoking habit, showing $22.3 \%$ prevalence of ever HS in age range 45-74 years, is the first conducted in the Varese Province using a large population sample. The data on heavy cigarette smoking presented in this paper, stratified by gender and age, may be used to monitor changes in the smoking habit and in the incidence of smoking-related illnesses at the provincial level.

Monaldi Arch Chest Dis 2010; 73: 4, 152-154.

Keywords: Prevalence cigarette smoking, Heavy smoker, Varese Province, Population survey.

1 Center for Thoracic Surgery, University of Insubria, Ospedale di Circolo di Varese,

2 Department of Medicine and Public Health, University of Verona, Verona, Italy.

Correspondence: Andrea Imperatori, Center for Thoracic Surgery, University of Insubria, Ospedale di Circolo, Viale Borri 57, 21100 Varese, Italy; e-mail: andrea.imperatori@uninsubria.it

\section{Introduction}

Cigarette smoking is one of the main causes of chronic disease and it is the sixth most common cause of death worldwide. The number of smoking-related deaths per year worldwide is estimated to be 1.7 million from cardiovascular diseases, 1 million from COPD and over 1 million from lung cancer $[1,2]$. The information on age and genderspecific smoking prevalence in the population can be used for several purposes related to prevention and treatment of the numerous chronic and lethal diseases caused by cigarette smoking (table 1). The prevalence of ever smokers - as defined by the Centers for Disease Control and Prevention, National Health Interview Survey (CDC-NHIS): current smokers of at least 1 cigarette/day and former smokers of at least 100 cigarettes in lifetime [3] - in the general population of Italy in the years 2002-2005, including both genders, was $24 \%$. This was lower than in several central and southern European countries (France, 25\%; Spain, 28\%; Germany, 34\%; Austria, $47 \%$ ) but higher than in other developed countries such as Finland (23\%) and Sweden (16\%) [4] and in the USA (21\%) [5].

Moreover, the smoking habit varies considerably across geographical areas within the same country and across age groups, as shown by the different smoking prevalence figures recorded in northern, central and southern Italy [6].

Smoking prevalence data has been published for the Italian regions [7], but generally this data is not known at a lower administrative level, i.e. that of the Italian provinces. To serve the purposes outlined in table 1 , the smoking prevalence figures and the information relating to pack/years smoked are needed also at the provincial level. As an example, the information on the prevalence of cigarette smoking in the Province of Varese, currently not available, could be used to estimate the smoking attributable deaths based on the Varese mortality registry data, thus allowing better provincial planning of how to deploy public health resources.

The aim of this paper is to report the smoking prevalence data that we recorded in a survey of a large sample of the general population of the Varese Province. As we were especially interested in evaluating the prevalence of heavy cigarette smoking as a risk factor for lung cancer, we carried out the smoking survey in the age range 45-74 years subjects, the fraction of the population recognised to present a significantly higher lung cancer risk. This study was approved by the Varese Hospital and Health District Ethics Committee. 
Table 1. - Use of smoking prevalence data

Smoking prevalence data in the population can be used to: a) monitor changes of smoking addiction prevalence

b) evaluate effectiveness of smoking cessation programmes

c) estimate the expected incidence of smoking-related diseases in future years

d) calculate the smoking attributable fraction of diseases

e) plan resources needed to treat the expected smokingrelated diseases

\section{Methods}

A survey on cigarette smoking was carried out in the year 2000 in the general population resident in communities widely scattered over the Varese Province. The information about smoking habit was anonymously collected by 47 general practitioners (GPs), by personal interview of the population of all adults 45-74 years old resident in the community of their public medical practice. The participation of the surveyed population was nearly complete, and included cumulatively 28,034 subjects (13,528 men and 14,506 women), a large sample $(9.3 \%)$ of the population in the same agerange 45-74 years $(300,384$ subjects) resident in the Varese Province [8, 9].

For the purpose of the current work, "current" heavy smokers (HS) were defined as subjects with history of active cigarette smoking of at least 10 pack/years ( $\mathrm{p}-\mathrm{y})$ at the survey time; smokers of at least $10 \mathrm{p}-\mathrm{y}$, who had quit smoking less than 10 years before were defined as "former" HS. These definitions identify current and former smokers with substantially high smoking related risk, documented by high p-y smoked. All other subjects were defined as non HS. The information on smoking habit collected by the GPs were rendered anonymous; data was pooled and stored in an encrypted database for analysis, complying with privacy regulations.

Prevalence figures of ever HS (current/former) and of non HS were tabulated, grouped by gender and by 5-year age-strata, specifying the sample size.

\section{Results}

Ever HS (both sexes combined) were $22.3 \%$ of the 28,034 subjects surveyed; current HS were $16.7 \%$ and former HS 5.5\%. Current HS were significantly younger than former HS (median age respectively 56 vs. 59 years; $\mathrm{p}<0.001)$. In the 13,528 male subjects surveyed the prevalence of ever HS was $34.4 \%$, significantly higher than in females (11.0\% of 14,506 surveyed; $\mathrm{p}<0.001)$.

The prevalence of ever HS is shown by gender and by age quintiles strata in tables 2-4. The median p-y in current HS was 33.9 (IQR: 22.6-48.0) and in former HS it was 32.4 (IQR 22.0-41.7), confirming a substantially high smoking-related risk.

\section{Discussion}

The definition of current HS and of former HS used in this paper identifies subjects with high median $\mathrm{p}-\mathrm{y}$, respectively $33.9 \mathrm{p}-\mathrm{y}$ in current $\mathrm{HS}$ and $32.4 \mathrm{p}-\mathrm{y}$ in former HS in the Varese Province. Median $p-y \geq 30$ is generally accepted as a high risk factor for the development of lung cancer [10]. The ISTAT survey of 2005 in the Lombardy region reported for subjects aged 45-74, both sexes combined, a $22.1 \%$ prevalence of current smokers [7]. However the ISTAT smoking prevalence data cannot be directly compared with our results because ISTAT referred to the CDC-NHIS definition of current smoker, which includes also a substantial proportion of light smokers (at least 1 cigarette/day) [3]; moreover, in the ISTAT survey the current smokers' p-y was not computed.

The information on cigarette smoking habit reported in the present paper was collected by 47 physicians GPs with public practices providing free medical care to adults of all ages, widely scattered over the Varese Province. The survey covered 28,034 individuals 45 to 74 years old, a large sample of the Varese population of the same agerange.

The HS prevalence figures that we reported were collected a decade ago (year 2000), therefore they are already considered to be "old" data. Nevertheless this is the first survey on the prevalence

Table 2. - Prevalence of heavy smokers (HS) in the year 2000 in the sampled Varese Province population of both genders, aged 45 to 74 years, by age strata

\begin{tabular}{lcccccc}
\hline Age & $\begin{array}{c}\text { N of Surveyed } \\
\text { Subjects }\end{array}$ & $\begin{array}{c}\text { \% of Total } \\
\text { Surveyed }\end{array}$ & $\begin{array}{c}\text { N (\%) of Ever } \\
\text { HS }\end{array}$ & $\begin{array}{c}N(\%) \text { of Current } \\
H S\end{array}$ & $\begin{array}{c}N(\%) \text { of Former } \\
H S\end{array}$ & $\begin{array}{c}\text { N }(\%) \text { of Non } \\
\text { HS }\end{array}$ \\
\hline $45-49 \mathrm{yrs}$ & 6,882 & 24.5 & $1,625(23.6)$ & $1,340(19.5)$ & $285(4.2)$ & $5,257(76.3)$ \\
$50-54 \mathrm{yrs}$ & 4,900 & 17.5 & $1,121(22.9)$ & $890(18.2)$ & $231(4.7)$ & $3,779(77.1)$ \\
$55-60 \mathrm{yrs}$ & 5,020 & 17.9 & $1,154(23.1)$ & $836(16,6)$ & $318(6.3)$ & $3,866(77)$ \\
$60-64 \mathrm{yrs}$ & 4,362 & 15.6 & $947(21.8)$ & $671(15,4)$ & $276(6.3)$ & $3,415(78.3)$ \\
$65-69 \mathrm{yrs}$ & 3,842 & 13.7 & $808(21.0)$ & $565(14.7)$ & $243(6.3)$ & $3,034(78.9)$ \\
$70-74 \mathrm{yrs}$ & 3,028 & 10.8 & $589(19.5)$ & $387(12.8)$ & $202(6.7)$ & $2,439(80.5)$ \\
\hline Total & 28,034 & 100 & $6,244(22.3)$ & $4,689(16.7)$ & $1,555(5.5)$ & $21,790(77.7)$ \\
\hline
\end{tabular}

Survey of 28,034 Varese Province residents (men, N=13,528; women, N=14,506). 
Table 3. - Prevalence of heavy smokers (HS) in the year 2000 in the sampled Varese Province male population $(\mathrm{N}=13,528)$, aged 45 to 74 years, by age strata

\begin{tabular}{lcccc}
\hline Age & $\begin{array}{c}\text { N }(\%) \text { of Ever } \\
\text { HS }\end{array}$ & $\begin{array}{c}N(\%) \text { of Current } \\
H S\end{array}$ & $\begin{array}{c}N(\%) \text { of Former } \\
H S\end{array}$ & $\begin{array}{c}\text { N }(\%) \text { of Non } \\
\text { HS }\end{array}$ \\
\hline $45-49 \mathrm{yrs}$ & $1,105(32.2 \%)$ & $874(25.4 \%)$ & $231(6.7 \%)$ & $2,329(67.8 \%)$ \\
$50-54 \mathrm{yrs}$ & $817(32.8 \%)$ & $624(25.1 \%)$ & $193(7.7 \%)$ & $1,671(67.2 \%)$ \\
$55-60 \mathrm{yrs}$ & $881(36.0 \%)$ & $608(24.7 \%)$ & $273(11.1 \%)$ & $1,575(64.1 \%)$ \\
$60-64 \mathrm{yrs}$ & $736(35.7 \%)$ & $491(23.8 \%)$ & $245(11.9 \%)$ & $1,329(64.4 \%)$ \\
$65-69 \mathrm{yrs}$ & $639(36.6 \%)$ & $423(24.2 \%)$ & $216(12.4 \%)$ & $8,108(63.4 \%)$ \\
$70-74 \mathrm{yrs}$ & $472(35.5 \%)$ & $297(22.2 \%)$ & $175(13.1 \%)$ & $866(64.7 \%)$ \\
\hline Total & $4,650(34.4 \%)$ & $3,317(24.5 \%)$ & $1,333(9.8 \%)$ & $8,878(65.6 \%)$ \\
\hline
\end{tabular}

Table 4. - Prevalence of heavy smokers (HS) in the year 2000 in the sampled Varese Province female population $(\mathrm{N}=14,506)$, aged 45 to 74 years, by age strata

\begin{tabular}{lcccc}
\hline Age & $\begin{array}{c}\text { N }(\%) \text { of Ever } \\
\text { HS }\end{array}$ & $\begin{array}{c}N(\%) \text { of Current } \\
H S\end{array}$ & $\begin{array}{c}N(\%) \text { of Former } \\
H S\end{array}$ & $\begin{array}{c}\text { N (\%) of Non } \\
\text { HS }\end{array}$ \\
\hline $45-49 \mathrm{yrs}$ & $521(15.1 \%)$ & $467(13.5 \%)$ & $54(1.6 \%)$ & $2,928(84.9 \%)$ \\
$50-54 \mathrm{yrs}$ & $303(12.6 \%)$ & $268(11.1 \%)$ & $35(1.5 \%)$ & $2,108(87.4 \%)$ \\
$55-60 \mathrm{yrs}$ & $273(10.7 \%)$ & $228(8.9 \%)$ & $45(1.7 \%)$ & $2,291(89.3 \%)$ \\
$60-64 \mathrm{yrs}$ & $211(9.2 \%)$ & $180(7.8 \%)$ & $31(1.4 \%)$ & $2,086(90.8 \%)$ \\
$65-69 \mathrm{yrs}$ & $169(8.1 \%)$ & $142(6.8 \%)$ & $27(1.3 \%)$ & $1,926(91.9 \%)$ \\
$70-74 \mathrm{yrs}$ & $117(7.0 \%)$ & $90(5.3 \%)$ & $27(1.6 \%)$ & $1,573(93.1 \%)$ \\
\hline Total & $1,594(11.0 \%)$ & $1,375(9.5 \%)$ & $219(1.5 \%)$ & $12,912(89.0 \%)$ \\
\hline
\end{tabular}

of HS that was ever conducted in the Varese Province, on a population sample that by size can be considered representative of the Province population $[8,9]$.

When the figures of smoking prevalence in the years after 2000 will become available for Varese, the data stratified by gender and by age quintiles presented in the present paper could be used to monitor changes in the smoking habit and in the incidence of smoking-related illnesses at the provincial level.

Smoking prevalence rates, combined with the information on the number of $p-y$ smoked, may be used to calculate the probability of lung cancer development in the population [11]. Remembering that for most lung cancers it takes more than 10 years to become clinically overt [12] the year 2000 smoking prevalence data that we have reported here can be useful to predict the probability of developing lung cancer in subsequent years in the Varese Province population.

\section{References}

1. Ezzati M, Lopez AD. Estimates of global mortality attributable to smoking in 2000. Lancet 2003; 362: 847-52.

2. Vineis P, Alavanja P, Buffler P, et al. Tobacco and cancer: recent epidemiological evidence. J Natl Cancer Inst 2004; 96: 99-106.

3. Centers for Disease Control and Prevention (CDC). Na- tional Health Information Survey (NHIS) - Adult Tobacco Use Information. Available on http://www.cdc. gov/nchs/nhis/tobacco/tobacco_glossary.htm. Accessed on Dec. 24, 2010.

4. WHO, 2007. European database on tobacco control. Available on line at: http://data.euro.who.int/tobacco/. Accessed on Dec. 10, 2010.

5. CDC (Center of Disease Control and Prevention) 2007. Cigarette smoking among adults - United States, 2006. MMWR Morb. Mortal. Wkly. Rep. 56, 1157-61.

6. Tramacere I, Gallus S, Zuccaro P, et al. Socio-demographic variation in smoking habitus. Italy, 2008. Prev Med 2009; 48: 213-7.

7. Condizioni di salute, fattori di rischio e ricorso ai servizi sanitari. Anno 2005 ISTAT. Available on http://www.istat.it/salastampa/comunicati/non_calendario/ 20070302_00/testointegrale.pdf. Accessed on Dec. 10, 2010.

8. Istituto Nazionale di Statistica ISTAT. Italian Population Census 2001. Available on http://dawinci.istat.it/. Accessed on Dec. 10, 2010.

9. Istituto Nazionale di Statistica ISTAT. DemoISTAT. Available on http://demo.istat.it/. Accessed on Dec. 10, 2010.

10. Strauss GM, Dominioni L, Jett JR, Freedman M, Grannis FW Jr. Como international conference position statement: lung cancer screening for early diagnosis 5 years after the 1998 Varese conference. Chest 2005; 127: 1146-1151.

11. Field JK, Duffy SW. Lung cancer screening: stratification of high risk populations. Oncology News 2008; 3: 6-8.

12. Wheatley D. Early detection of lung cancer: screening the high risk group. Oncology News 2008; 3: 4. 